\title{
Job satisfaction and leaving intentions of midwives: analysis of a multinational cross-sectional survey
}

\author{
DARJA JAROSOVA Rn, Msc, PhD ${ }^{1}$, ELENA GURKOVA Rn, MSc, PhD ${ }^{2}$, ALVISA PALESE Rn, Bsc, MSc ${ }^{3}$, \\ GLORIA GODEAS Rm, $\mathrm{Msc}^{4}$, KATARINA ZIAKOVA RN, Msc, PhD ${ }^{5}$, MI SOOK SONG RN, MPH, PhD ${ }^{6}$, \\ JONGWON LEE Rn, MSN, PhD Candidate ${ }^{7}$, RAUL CORDEIRO Rn, MSc, PhD ${ }^{8}$, SALLY WAI-CHI CHAN RN, PhD, \\ FAAN $^{9}$, BEATA BABIARCZYK RN, MSN, HSD ${ }^{10}$, MALGORZATA FRAS RM, mSN ${ }^{11}$ and DANIELA \\ NEDVEDOVA RM, MSc, PhD Candidate ${ }^{12}$
}

${ }^{1}$ Associate Professor, ${ }^{12}$ Assistant Professor, Department of Nursing and Midwifery, Faculty of Medicine, University of Ostrava, Ostrava, Czech Republic, ${ }^{2}$ Associate Professor, Department of Nursing, Faculty of Health Care, University of Presov, Presov, Slovakia, ${ }^{3}$ Associate Professor, Department of Medical and Biological Sciences, University of Udine, Udine, Italy ${ }^{4}$ Clinical Midwife, Palmanova Udine Hospital, Udine, Italy, ${ }^{5}$ Associate Professor, Head of Department of Nursing, Jesseniuss Faculty of Medicine in Martin, Comenius University in Bratislava, Martin, Slovak Republic, ${ }^{6}$ Professor, College of Nursing, Ajou University, Suwon, South Korea, ${ }^{7}$ Education Department, Korean Nurses Association, Seoul, South Korea, ${ }^{8}$ Associate Professor, Department of Health Sciences and Technologies, School of Health, Polytechnic Institute of Portalegre, Portalegre, Portugal, ${ }^{9}$ Professor, Head of School of Nursing and Midwifery, Faculty of Health and Medicine, The University of Newcastle, Newcastle, New South Wales, Australia and ${ }^{10}$ Associate Professor, ${ }^{11}$ Senior Lecturer, Faculty of Health Sciences, University of Bielsko-Biała, Bielsko-Biała, Poland

Correspondence

Darja Jarosova

Faculty of Medicine

University of Ostrava

Syllabova 19

70300 Ostrava 3

Czech Republic

E-mail:darja.jarosova@osu.cz
JAROSOVA D., GURKOVA E., PALESE A., GODEAS G., ZIAKOVA K., SONG M.S., LEE J., CORDEIRO R., CHAN S.W.-C., BABIARCZYK B., FRAS M. \& NEDVEDOVA D. (2015) Journal of Nursing Management

Job satisfaction and leaving intentions of midwives: analysis of a multinational cross-sectional survey

Aim To investigate the relationship between turnover intentions and job satisfaction among hospital midwives from seven countries and to determine how the related variables differ between countries.

Background Studies investigating professional turnover and job satisfaction among midwives are limited in scope.

Method A cross-sectional descriptive survey was used to investigate the intended turnover and job satisfaction relationship among 1190 hospital midwives in European and Asian countries. Data were collected using a set of questionnaires that included questions regarding the leaving intentions of midwives and the McCloskey/Mueller satisfaction scale.

Results Midwives were least satisfied with their extrinsic rewards and professional opportunities and with the balance between family and work.

Significant differences were found in all domains of job satisfaction according to midwives' intentions to leave their current workplace in hospital or profession of midwife, and to work abroad.

Conclusion There are some general satisfying and dissatisfying elements for the profession of midwife across different countries.

Implications for nursing management The results highlight the importance of understanding midwives' leaving intentions and related factors across different countries. To prevent midwife turnover, health-care managers should gain greater insight into the early stage of midwives' turnover intention.

Keywords: job satisfaction, midwifery, turnover intention

Accepted for publication: 21 September 2014 


\section{Introduction}

Human resources represent a vital component of the workforce and also ensure high-quality services. The retention of health-care workers in an organisation helps to ensure the quality of care and maintain the financial balance of the overall costs of health care. The retention of health-care personnel and a stable workforce are important for budget management in health-care facilities because of the additional costs of re-hiring and orienting new staff.

Job satisfaction is often discussed within health professions in relation to the retention, instability of the available workforce and the shortage of health-care workers. Compared with the growth of research concerning nurses' job satisfaction, few studies have focused on midwives (Bodur 2002, Hampton \& Peterson 2012, Rouleau et al. 2012). In this regard, Hampton and Peterson (2012) state that most of the current studies have had a limited scope focusing only on one or two aspects of midwives' job satisfaction, or primarily just on overall job satisfaction. The subject of some studies has been a description of job satisfaction in relation to ensuring the continuity of care (Cattrell et al. 2005), or a comparison with other health-care workers, most frequently nurses (Bodur 2002, O'Keeffe et al. 2013). Job satisfaction in midwives has been investigated in relation to more specific features of this profession, such as the burnout syndrome (Rouleau et al. 2012); work-related stress and overload (Skinner et al. 2012); structural, psychological, critical social empowerment (Casey et al. 2010); job requirements, working conditions (Hampton \& Peterson 2012) and demographic characteristics (Lazarus et al. 2005, Hampton \& Peterson 2012). The relationship between job satisfaction and instability of the available workforce in midwives has been investigated in relation to the specific economic and social-cultural context of a few countries (Rouleau et al. 2012).

\section{Overview of the literature}

The turnover of health-care workers and related determinants have been of interest to researchers from different disciplines for several decades (Coomber \& Barriball 2007, Hasselhorn et al. 2008, Simon et al. 2010, Hayes et al. 2012). Ajzen's (1991) theory of planned behaviour has explained factors that predict actual turnover and describe the relationships between a person's attitudes, intentions and turnover behaviour. Attitudes towards behaviour, subjective norms and perceptions of behavioural control have been identified as predictors (i.e. antecedents) of behavioural intentions (Ajzen 1991). Based on this theory, Coomber and Barriball (2007) argued that the cognitive process of turnover intention (i.e. intent to leave) was an important predictor of actual turnover. According to Takase (2010), turnover intent is often triggered by negative psychological responses to organisational, work-related, employment factors or external (i.e. work-life balance) aspects of a job. The psychological responses evolve into gradual withdrawal cognition and behaviours, and lead to actual turnover (Takase 2010).

The psychological component of turnover intention is the starting point of the multi-stage turnover reaction (Takase 2010). Coomber and Barriball (2007) described turnover intention (or intent to leave/stay) as an outcome of affective variables, such as job satisfaction. Ravari et al. (2012) summarised that job satisfaction could be defined from various aspects: as an affective orientation towards a job or its components (Mueller \& McCloskey 1990, Adams \& Bond 2000); as an attitude towards the job (Meeusen et al. 2010); as an expectation from the job; as a belief system (i.e. values and norms); or as a multidimensional construct (i.e. different elements of the job). All this infers that job satisfaction is an important psychological component of turnover intention.

\section{Aim}

The aim of this study was to investigate the relationship between turnover intentions and job satisfaction among hospital midwives from seven countries and to determine differences, if any, between the countries.

Nursing and midwifery workforces are increasingly moving and migrating from one country to another, for example, within the European Union or from developing to developed countries. The findings of this study may aid in a better understanding of the reasons why health-care professionals move and in guiding decisions at a political level to establish stable healthcare workforces nationally and internationally.

\section{Sample}

The sample consisted of 1190 hospital midwives from five European countries (Czech Republic, Italy, Poland, Portugal and Slovakia) and two Asian countries (Singapore and South Korea). Data collection took place at obstetric, gynaecological and paediatric departments of hospitals in each country. A total of 45 hospitals from six countries participated in the 
study $(8$ hospitals from Czech Republic; 6 hospitals from Italy; 7 hospitals from Poland; 1 hospital from Singapore; 8 hospitals from Slovakia; and 15 hospitals from South Korea). In Portugal, data were collected from the National Nursing Association's members conducting a nationwide electronic survey, with all data being self-reported via an online web-based portal.

The respondents were recruited between March and May 2013. The inclusion criteria were as follows: a participant was expected be a registered midwife, worked in obstetric and gynaecological departments at least for one year, and had fluency in the native language of that particular country. The respondents were requested to complete a questionnaire and drop it in a box placed in the manager's office in a sealed envelope.

A total of 1520 questionnaires were distributed to the eligible respondents in the six participating countries (with the exception of Portugal), of which 1122 were returned. The overall response rate was $73.7 \%$, ranging from $63.7 \%$ (Poland) to $83.2 \%$ (Slovakia). In Portugal, the response rate was $4.6 \%$, mostly because it was a nationwide web-based survey.

\section{Methods}

The same data collection tools were adopted in all countries. These measured the three main areas: turnover intentions, job satisfaction and a respondent's background information.

\section{Turnover intentions}

The questions explored three types of turnover intentions: to leave the profession (i.e. professional intention), to leave the organisation (i.e. institutional intention) and to work abroad (i.e. professional migration). The respondents were asked to rate how often they had considered leaving their current workplace and profession and had considered working abroad in the previous 6 months on a scale ranging from 0 ('never') to 4 ('very often').

\section{Job satisfaction}

Domains of job satisfaction were measured by eight subscales of the McCloskey/Mueller Satisfaction Scale (MMSS). The instrument is composed of 31 items grouped under eight subscales: satisfaction with extrinsic rewards (3 items), scheduling (6 items), family/work balance (3 items), co-workers (2 items), interaction (4 items), professional opportunities (4 items), praise/recognition (4 items) and control/responsibility (5 items). Each item is scored from 1 to 5, with 1 corresponding to 'very dissatisfied' and 5 corresponding to 'very satisfied'. Cronbach's alpha values for each of the eight subscales in our study ranged from 0.526 to 0.812 ; the alpha for the global scale was 0.915 .

We obtained the authors' permission to use the MMSS in this study. The questionnaire was translated only if translations into the national languages of the participating countries were not available; Polish, Portuguese, Italian, Malaysian and Korean translations were needed. The MMSS was translated by standard forward and back translation procedures.

\section{Background and work-related information}

Socio-demographic data including age, education level and work-related variables were collected.

\section{Statistical analysis}

The statistical analysis was performed using the statistical software package STATA 13.0/IC (StataCorp: Texas). For group comparisons, the Kruskal-Wallis rank test was performed where appropriate. Proportion comparisons were carried out with the Pearson's chi-square test. A value of $P<0.05$ was set to indicate statistical significance for all comparisons.

\section{Results}

\section{Socio-demographic characteristics of the participants}

The majority of respondents were female (99\%); their mean age ranged from 36.2 years (Italy) to 44.6 years (Poland). The mean duration of work experience was 15.6 years, ranging from 9.6 years (Portugal) to 21.8 years (Poland). The respondents had been in their current hospital departments for a mean of 11.1 years, ranging from 6.7 years (Portugal) to 16.7 years (Poland) (Table 1 ). The majority of the respondents $(94.3 \%, n=1122)$ worked full time and $5.5 \%(n=65)$ worked part time. A significant proportion $(33.4 \%)$ of the midwives had a bachelor's degree. Approximately every third $(39.0 \%, n=462)$ respondent worked in delivery rooms; around every fourth $(24.2 \%, n=287)$ worked in obstetric departments; $14.4 \%(n=171)$ worked in gynaecological depart- 
Table 1

Demographic characteristic of the multi-national sample

\begin{tabular}{|c|c|c|c|c|c|c|c|c|}
\hline Variable & Czech Republic & Italy & Poland & Portugal & Singapore & Slovakia & South Korea & Total \\
\hline Male: $n(\%)$ & $0(0)$ & $1(0.6)$ & $0(0)$ & $11(9.6)$ & $0(0)$ & $0(0)$ & $0(0)$ & $12(1.0)$ \\
\hline Age in years: $M(S D)$ & $38.6(11.5)$ & $36.2(9.5)$ & $44.6(8.1)$ & $41.1(8.1)$ & $36.7(11.9)$ & $39.3(9.6)$ & $43.5(9.9)$ & $40.0(10.4)$ \\
\hline \multicolumn{9}{|l|}{ Education: $n(\%)$} \\
\hline Vocational & $67(25.8)$ & $12(7.1)$ & $88(50)$ & $65(57)$ & $31(34.4)$ & 39 (18.8) & $7(4.6)$ & $309(26.4)$ \\
\hline Diploma & $84(32.3)$ & $45(26.5)$ & $59(33.5)$ & $9(7.9)$ & $15(16.7)$ & 61 (29.3) & $61(39.8)$ & $334(28.5)$ \\
\hline $\mathrm{PhD}$ & $0(0)$ & $9(5.3)$ & $0(0)$ & $1(0.9)$ & $0(0)$ & $1(0.5)$ & $3(2.0)$ & $14(1.2)$ \\
\hline $\begin{array}{l}\text { Work experience in } \\
\text { years: } M(S D)\end{array}$ & $15.6(11.9)$ & $13.0(10.5)$ & $21.8(8.8)$ & $9.6(7.7)$ & $12.2(9.7)$ & $17.3(10.4)$ & $15.7(9.1)$ & $15.6(10.6)$ \\
\hline $\begin{array}{l}\text { Work experience on } \\
\text { department: } M(S D)\end{array}$ & $10.6(9.7)$ & $9.2(8.5)$ & $16.7(9.4)$ & $6.7(5.9)$ & $7.7(7.5)$ & $13.7(10.1)$ & $9.0(7.9)$ & $11.1(9.4)$ \\
\hline
\end{tabular}

ments; $2.0 \%(n=24)$ in intensive care units; $5.2 \%$ $(n=61)$ in outpatient settings; and $15.2 \%(n=179)$ worked in other departments (neonatology, paediatrics, etc.).

\section{Intention to leave the current workplace or midwifery profession or to work abroad}

Approximately every third $(37.8 \%, n=448)$ respondent considered leaving the organisation; every fifth $(21.6 \%, n=255)$ considered leaving the profession and every fourth $(26.0 \%, n=308)$ considered leaving the country in order to practise the profession abroad (Table 2). Significant differences in the intentions to leave the current workplace were found between the countries (Pearson's chi-square test $=18.44 ; P=0.005)$. However, there were no differences in the intentions to leave the midwifery profession (Pearson's chi-square test $=9.96$; $P=0.12$ ). Significant differences were observed in the intentions to leave the country in order to practise the profession abroad (Pearson's chi-square test $=112.53 ; P=0.000)$. Considerable differences between the respondents from the participating countries regarding the change of the current workplace were found, with a rather high proportion coming from Singapore and Italy and smaller proportions from the Czech Republic, Poland and South Korea. The smallest proportion came from South Korea (Table 3). Approximately $21-22 \%$ of the midwives considered leaving the profession in the Czech Republic, Portugal, Poland, Slovakia and Italy. The highest percentage of the respondents who considered leaving the profession came from Singapore. The highest proportion of midwives wanting to work abroad was in Portugal, followed by Singapore and Italy.

Table 2

Turnover intentions of midwives

\begin{tabular}{|c|c|c|c|c|c|c|}
\hline Country & $\begin{array}{l}\text { Intention to leave } \\
\text { workplace (\%) }\end{array}$ & $\begin{array}{l}\text { Frequency of intentions } \\
\text { to leave workplace } M(S D)\end{array}$ & $\begin{array}{l}\text { Intention to leave } \\
\text { profession (\%) }\end{array}$ & $\begin{array}{c}\text { Frequency of } \\
\text { intentions to } \\
\text { leave profession } \\
M(S D)\end{array}$ & $\begin{array}{l}\text { Intention to work } \\
\text { abroad (\%) }\end{array}$ & $\begin{array}{l}\text { Frequency of } \\
\text { intentions to work } \\
\text { abroad } M(S D)\end{array}$ \\
\hline $\begin{array}{l}\text { Czech Republic } \\
(n=260)\end{array}$ & $82(31.5)$ & $2.56(0.72)$ & $55(21.2)$ & $2.75(0.84)$ & $33(12.7)$ & $2.87(0.85)$ \\
\hline Italy $(n=174)$ & $72(41.4)$ & $2.57(0.86)$ & $36(21.1)$ & $3.03(0.80)$ & $58(33.7)$ & $2.67(0.87)$ \\
\hline Singapore $(n=95)$ & $47(49.5)$ & $2.53(0.95)$ & 32 (32.7) & $2.46(1.00)$ & $37(37.4)$ & $2.66(0.91)$ \\
\hline Slovakia $(n=208)$ & $76(36.5)$ & $2.45(0.82)$ & $46(22.1)$ & $2.39(0.80)$ & $50(24.0)$ & $2.52(0.76)$ \\
\hline $\begin{array}{l}\text { South Korea } \\
(n=155)\end{array}$ & $54(34.8)$ & $2.61(0.56)$ & $25(16.1)$ & $2.68(0.63)$ & $30(19.4)$ & $2.52(0.69)$ \\
\hline Total $(n=1182)$ & $448(37.8)$ & $2.41(0.86)$ & $255(21.6)$ & $2.55(0.90)$ & $308(26.0)$ & $2.51(0.87)$ \\
\hline
\end{tabular}

Percentage of midwives reported that they considering leaving actual workplace profession or to work abroad in selected country. 
Table 3

Difference between countries in job satisfaction

\begin{tabular}{|c|c|c|c|c|c|c|c|c|}
\hline Variable & $\begin{array}{c}\text { Czech Republic } \\
M(S D)\end{array}$ & $\begin{array}{c}\text { Italy } \\
M(S D)\end{array}$ & $\begin{array}{l}\text { Poland } \\
M(S D)\end{array}$ & $\begin{array}{l}\text { Portugal } \\
M(S D)\end{array}$ & $\begin{array}{c}\text { South Korea } \\
M(S D)\end{array}$ & $\begin{array}{c}\text { Singapore } \\
M(S D)\end{array}$ & $\begin{array}{l}\text { Slovakia } \\
M(S D)\end{array}$ & $\begin{array}{l}\text { Total } \\
M(S D)\end{array}$ \\
\hline Job satisfaction (overall) & $3.15(0.49)$ & $3.05(0.58)$ & $2.95(0.58)$ & $2.91(0.59)$ & $3.04(0.51)$ & $3.28(0.49)$ & $3.08(0.58)$ & $3.06 * * *(0.55)$ \\
\hline Extrinsic rewards & $2.73(0.73)$ & $2.69(0.75)$ & $2.28(0.82)$ & $2.18(0.77)$ & $2.91(0.71)$ & $3.21(0.77)$ & $2.45(0.88)$ & $2.61 * * *(0.82)$ \\
\hline Scheduling & $3.13(0.73)$ & $2.96(0.84)$ & $3.15(0.78)$ & $3.22(0.86)$ & $3.03(0.68)$ & $3.25(0.78)$ & $3.07(0.75)$ & $3.10 * * \quad(0.77)$ \\
\hline Family/work balance & $3.08(0.68)$ & $2.62(0.86)$ & $2.75(0.83)$ & $2.61(0.73)$ & $2.65(0.82)$ & $3.14(0.67)$ & $2.74(0.74)$ & $2.81 * * *(0.78)$ \\
\hline Co-workers & $3.84(0.61)$ & $3.74(0.76)$ & $3.71(0.88)$ & $3.29(0.93)$ & $3.40(0.64)$ & $3.70(0.60)$ & $3.86(0.85)$ & $3.69 * * *(0.78)$ \\
\hline Praise/recognition & $3.23(0.80)$ & $3.23(0.85)$ & $3.05(0.79)$ & $3.07(0.90)$ & $3.39(0.68)$ & $3.48(0.60)$ & $3.25(0.90)$ & $3.23 * * *(0.81)$ \\
\hline Control/responsibility & $2.99(0.72)$ & $3.10(0.78)$ & $2.79(0.83)$ & $2.68(0.84)$ & $3.07(0.59)$ & $3.22(0.65)$ & $3.01(0.83)$ & $2.98 * * *(0.77)$ \\
\hline
\end{tabular}

$P<0.05 ; * * P<0.01 ; * * * P<0.001$.

\section{Incidence of turnover intentions}

The incidence of turnover intentions was investigated within the group of midwives who reported that they had considered leaving their current workplace or midwifery profession or considered working abroad during the past 6 months (Table 2). There were significant differences between the participating countries in the mean rates of midwives who had considered changing the current workplace $(P<0.001)$, leaving the midwifery profession $(P<0.001)$ or leaving the country in order to practise the profession abroad $(P<0.05)$.

\section{Job satisfaction and the respondents' demographic backgrounds}

The participating countries differed considerably also with respect to overall job satisfaction and its domains, with better mean scores especially in Singapore $($ mean $=3.28, \mathrm{SD}=0.49)$, and more adverse scores in Portugal $($ mean $=2.91, \mathrm{SD}=0.59)($ Table 3$)$. Overall, the respondents in the participating countries were most satisfied with their relationship with co-workers and most dissatisfied with extrinsic rewards. The midpoint of the Likert-type scale (3.00-3.49) represents balanced satisfaction (Prosen \& Piskar 2013). The mean scores of overall job satisfaction demonstrate that midwives are neither significantly satisfied nor dissatisfied. Nevertheless, it is important to note a trend that the respondents were most satisfied with the relationship with coworkers $($ mean $=3.69, \mathrm{SD}=0.78)$ and interaction opportunities $($ mean $=3.37, \mathrm{SD}=0.72)$, while they were least satisfied with their extrinsic rewards $($ mean $=2.61, \mathrm{SD}=0.82)$, professional opportunities $($ mean $=2.83, \mathrm{SD}=0.74)$ and the balance between family and work $($ mean $=2.81, \mathrm{SD}=0.78)($ Table 3$)$.

Non-parametric tests (Kruskal-Wallis) were conducted to analyse the relationships between the categorical demographic variables and the MMSS subscales (Table 4). Significant differences were found between the type of workplace (i.e. hospital ward) and overall job satisfaction $(P<0.01)$, satisfaction with extrinsic rewards $(P<0.05)$, scheduling $(P<0.01)$, balance between family and work $(P<0.01)$, relationship with co-workers $(P<0.01)$ and professional opportunities $(P<0.01)$. Significant differences were also found between the years of experience and satisfaction with scheduling $(P<0.01)$, balance between family and work $(P<0.05)$ and control/responsibility $(P<0.05)$. The results show that midwives with $26-30$ years of work experience were more satisfied with scheduling, balance between family and work and control/ responsibility than respondents in the other age groups. All MMSS subscales, with the exception of 'satisfaction with praise/recognition', demonstrated significant differences in relation to the respondents' age. Significant differences were also found between the level of education and satisfaction with extrinsic rewards $(P<0.001)$ and scheduling $(P<0.001)$. The results demonstrated that midwives with a master's and higher degrees were more satisfied (mean $=2.78, \mathrm{SD}=0.81$ ) with extrinsic reward than those respondents with other educational backgrounds. However, midwives with vocational training $($ mean $=3.23, \mathrm{SD}=0.73$ ) were more satisfied with their scheduling than the other respondents.

\section{Job satisfaction and turnover intentions}

It is important to note that the job satisfaction of midwives differed by the intention to leave the current workplace, the nursing profession and intention to work abroad (Table 5). Midwives who did not consider leaving the current workplace (mean $=3.19, \quad \mathrm{SD}=0.53$ vs. intention to leave 
Table 4

The relationships between demographic variables and the MMSS subscales

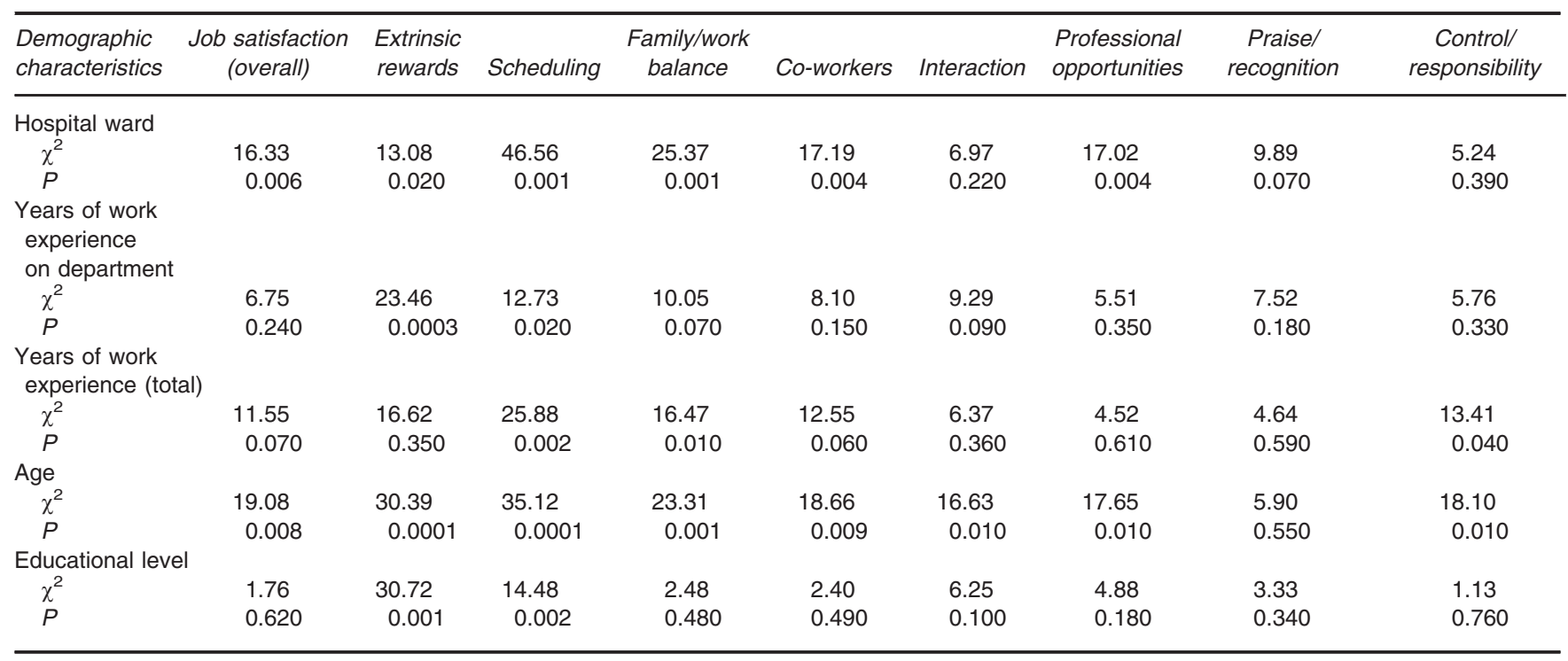

mean $=2.85, \mathrm{SD}=0.52)$, profession $($ mean $=3.14$, $\mathrm{SD}=0.54$ s. mean $=2.81, \mathrm{SD}=0.52$ ) or working abroad $($ mean $=3.12, \mathrm{SD}=0.54$ vs. mean $=2.92$, $\mathrm{SD}=0.56)$ reported a higher level of job satisfaction in all subscales of the MMSS than those respondents who had reported intentions to leave.

\section{Discussion}

The aim of this analysis was to investigate the relationship between job satisfaction and turnover inten- tions among midwives. Despite differences in how health care is organised and resourced, our cross sectional data suggest that all seven countries studied face problems with midwives' job dissatisfaction and turnover intentions. Hampton and Peterson (2012) reported that many job satisfaction studies in midwife populations had a limited scope. Compared with multinational studies investigating factors influencing nurses' institutional or professional turnover intentions (Hasselhorn et al. 2003, 2008, Simon et al. 2010, Aiken et al. 2012) and job satisfaction, the number of

Table 5

The relationships between turnover intentions and the MMSS subscales

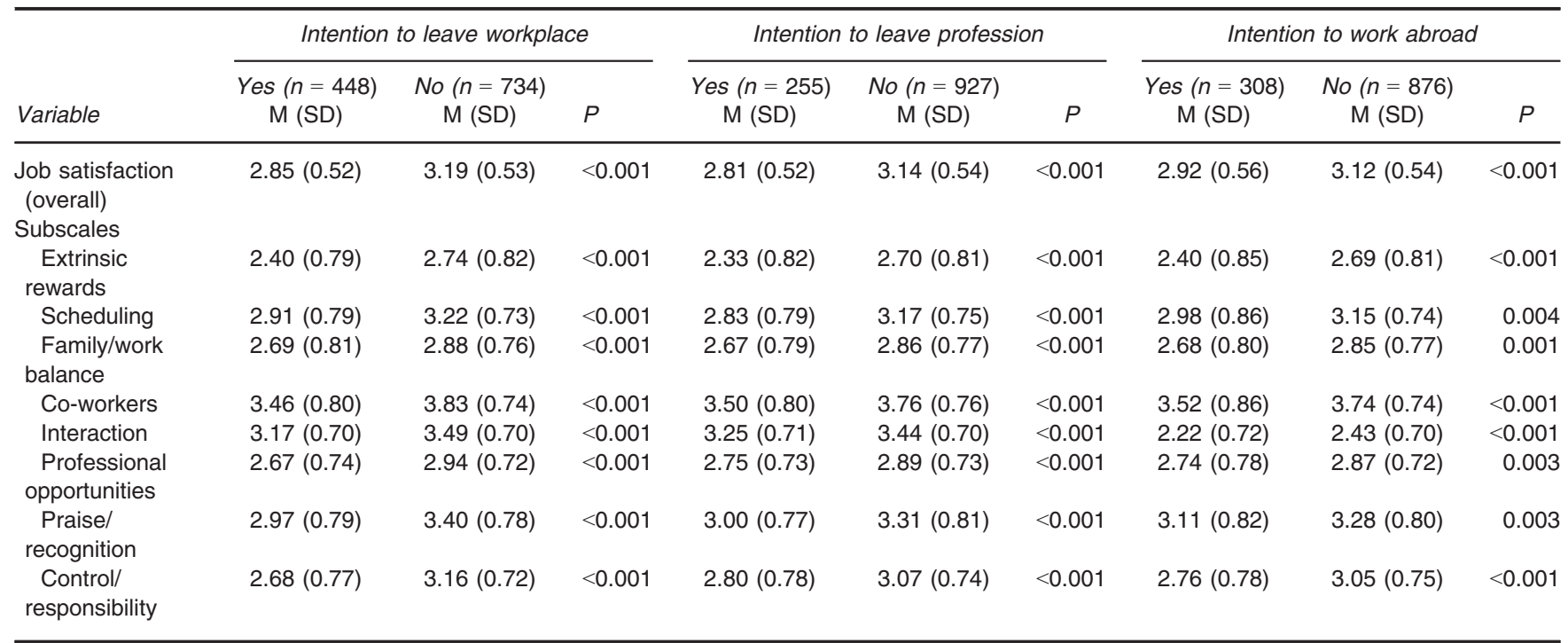


studies investigating these issues in midwives has been low. The strength of the present study is the crossnational design and the use of valid and reliable instruments, which allowed comparisons of the midwife populations between the participating countries using scientific methods.

The present study also indicates significant differences between the studied countries in all domains of midwives' job satisfaction and intentions to leave their current workplace or profession and to work abroad. Those midwives who did not consider leaving their workplace or profession or working abroad reported consistently higher job satisfaction in all the measured domains. Shen et al. (2004) conducted a literature review a few years ago, reporting that working hours, workload and work schedules are factors contributing to midwives' job satisfaction. In a more recent study, Rouleau et al. (2012) investigated job satisfaction, burnout, intention to quit and professional mobility among midwives in Senegal. The results demonstrated that despite nearly two-thirds $(58.9 \%)$ of the midwives reporting the intention to quit within a year, mainly to pursue new professional training, only $9 \%$ annual turnover was found in the study (41/226 over 2 years).

The job satisfaction of midwives working in hospitals is influenced by a variety of factors (Hampton \& Peterson 2012, Rouleau et al. 2012). Therefore, it was natural that some variation was found in scores between the demographic factors and job satisfaction in the present study. Several studies indicated inconsistent results in terms of the relationship between demographic background characteristics and job satisfaction in midwives. The significance of a respondent's age and years of experience was established in several nursing studies (Stordeur et al. 2003, Li \& Lambert 2008, Gurková et al. 2013). In the NEXT study (Stordeur et al. 2003) a curvilinear relationship between job satisfaction, age and seniority was found; the scores were higher in the lowest and highest age groups and in the years of seniority and lower after up to 5 years of experience from graduation. However, studies in Turkish midwives (Bodur 2002, Oncel et al. 2007) did not find a significant relationship between the length of employment and job satisfaction. Moreover, a study of Estonian midwives found no significant association between job satisfaction and age, ethnicity, work abroad or increased responsibility (Lazarus et al. 2005). On the other hand, the results of another study (Aksu et al. 2002) confirmed a positive relationship between length of employment and job satisfaction. The present study found significant differences between the midwives' years of work experience and satisfaction in three subscales - satisfaction with scheduling, balance between family and work, and control/responsibility. Differences in job satisfaction by age in all domains of job satisfaction, except with praise/recognition, were an interesting finding. The higher satisfaction in these domains could be explained by the respondents' better knowledge of nursing care, increasing benefits linked to seniority (i.e. salary or schedules) and decreasing external demands (e.g. work-home interference) (Stordeur et al. 2003).

The present study found that the overall job satisfaction and the domains of job satisfaction, such as satisfaction with extrinsic rewards, scheduling, balance between family and work, relationship with co-workers and professional opportunities, were significantly related with the workplace and type of employment. Hampton and Peterson (2012) also reported similar findings. They compared the association between job satisfaction factors (i.e. satisfaction with physician interactions, pay, organisational policies, job requirements and respect of physicians) and overall job satisfaction across different workplaces (i.e. government agencies, educational institutions, hospitals, physicians' offices and others). Their results showed, among other things, that the overall job satisfaction of midwives employed by hospitals was positively related to their satisfaction with physician interaction, job requirements, salary level and organisational policies (Hampton \& Peterson 2012).

In an earlier study, Bodur (2002) reported that health-care workers, including general practitioners, nurses and midwives, varied. This study also showed that midwives had the lowest satisfaction scores in comparison with general practitioners and nurses at public health centres in Turkey. The main reason for these midwives' dissatisfaction may have been the difficulty in carrying out their job in accordance with the administrative regulations in Turkey. In the present sample, midwives were least satisfied with their extrinsic rewards and professional opportunities and with the balance between family and work. These aspects associated with job satisfaction may be related more closely to the role of midwives rather than their work environment. Shen et al. (2004) reported that career development, promotion and appreciation of contribution were important factors for the retention of midwives. In their study of 562 registered nurses and midwives, Skinner et al. (2012) concluded that work enjoyment and feeling well suited to the particular type of work were related to job satisfaction. 
Similarly, satisfaction with the relationship with coworkers and interaction opportunities were identified as the most satisfying aspects of work in several nursing studies (Ellenbecker 2005, Leung et al. 2007, Gurková et al. 2013). Our results suggest that the domains of job satisfaction or dissatisfaction and leaving intentions are remarkably similar across Europe and in Asia, even though the measured scores vary between countries.

\section{Limitations}

The limitations of this study include its cross-sectional design, which did not allow a causal conclusion. Another limitation is concerned with the convenience sample. Our sample is not representative because the respondents were not randomly selected from the midwife populations working in hospitals in the participating countries. The study subjects came from a limited number of all the hospitals in the participating countries.

\section{Conclusion}

This study provides insights into job satisfaction of midwives across different countries, health-care systems, types of midwifery education and practise. Midwives were least satisfied with their extrinsic rewards and professional opportunities and the balance between family and work. Significant differences were found in all domains of job satisfaction and these were related to midwives' intentions to leave the current workplace in hospital or profession, and to work abroad. In addition, there were significant differences in job satisfaction and intentions to leave between countries.

\section{Implication for nursing management}

The relationship of job satisfaction with not only intention to leave the organisation but also intention to leave the profession and intention to work abroad may have implications for development of the midwifery profession at institutional and national levels. Our cross-sectional data suggest that all seven countries studied face problems of midwives' job dissatisfaction and leaving intentions. From occupational and social-political points of view, it is of interest whether and to what extent midwives leave their profession due to certain working conditions. The results of this study confirmed that job dissatisfaction is associated with professional and institutional turnover intentions. Further studies should focus on investigating the reasons and circumstances surrounding premature departure from the profession of midwife.

Job satisfaction is influenced by many factors that derive from the work itself and from the work environment (Prosen \& Piskar 2013). The present study provides insights into some of the factors that could have an important relationship with the domains of midwives' job satisfaction. Factors related to overall job satisfaction of midwives in this study were associated with the type of workplace, years of work experience and age. The study also confirmed some general satisfying and dissatisfying elements for the profession of midwife across different countries. Midwives in our sample were least satisfied with their extrinsic rewards and professional opportunities and with the balance between family and work. The findings suggest that only some aspects of job satisfaction can be controlled by the hospitals or health-care managers (e.g. extrinsic rewards). Similar to financial reward, other factors such as the balance between family and work or the professional development (e.g. cooperation with nursing faculties or participation in nursing research) may be equally important. Nurse managers must identify the contributors of job satisfaction in their own organisations. They should understand that these aspects may relate more closely to the role and career development of the midwife rather than to the work environment. There is empirical evidence that opportunities for career growth, learning and development provide a very important recruiting strategy. Nurse managers should consider implementing comprehensive career development programmes made up of career ladders, career paths and management development as part of a hospital's recruitment and retention strategic plan (Wilkes \& Bartley 2007). Nurse administrators and managers should consider the following: (1) implementing procedures for assessing job satisfaction on a regular basis; (2) implementing a comprehensive career development programme and incorporating a mentoring programme in the workplace that could empower midwives to develop personally and professionally; and (3) assessing other factors that enhance retention besides satisfaction and incorporating these factors in the climate of the organisation.

\section{Acknowledgements}

We thank all the midwives who participated in the study and provided us with the data. We also gratefully acknowledge the help with collecting data from colleagues in the universities and hospitals/centres. The authors would like to thank Hana Tomaskova, 
$\mathrm{PhD}$ (Center for Biostatistics, University of Ostrava) for her support in statistical analyses.

\section{Source of funding}

The authors did not receive any funding for this paper.

\section{Ethical approval}

The international study was coordinated by the Faculty of Medicine, University of Ostrava (Czech Republic). Therefore, the study was approved by the institutional Ethics Committee. Ethical research requirements for conducting research on human subjects were met for all of the hospitals in the study, as well as the investigators' university. In Portugal, the study was approved by the Ethics Committee of the National Nursing Association.

\section{References}

Adams A. \& Bond S. (2000) Hospital nurses' job satisfaction, individual and organizational characteristics. Journal of Advanced Nursing 32 (3), 536-543.

Aiken L.H., Sermeus W., Van den Heede K. et al. (2012) Patient safety, satisfaction, and quality of hospital care: cross sectional surveys of nurses and patients in 12 countries in Europe and the United States. British Medical Journal (Online). Available at: http://www.bmj.com/content/344/ bmj.e1717, accessed 20 January 2014.

Ajzen I. (1991) Theory of planned behavior. Organizational Behavior and Human Decision Processes 50, 179-211.

Aksu G., Acuner A.M. \& Tabak R.S. (2002) A study on job satisfaction of managers in the central and provincial organizations of the Ministry of Health (Ankara Example). Ankara Universitesi. Tip Fakultesi Mecmuasi 55 (2), 271-282.

Bodur S. (2002) Job satisfaction of health care staff employed at health centres in Turkey. Occupational Medicine 52 (6), 353-355.

Casey M., Saunders J. \& O’Hara T. (2010) Impact of critical social empowerment on psychological empowerment and job satisfaction in nursing and midwifery settings. Journal of Nursing Management 18 (1), 24-34.

Cattrell R., Lavender T., Wallymahmed A., Kingdon C. \& Riley J. (2005) Postnatal care: what matters to midwives. British Journal of Midwifery 13 (2), 206-213.

Coomber B. \& Barriball L.K. (2007) Impact of job satisfaction components on intent to leave and turnover for hospitalbased nurses: a review of the research literature. International Journal of Nursing Studies 44 (2), 297-314.

Ellenbecker C.H. (2005) Agencies make a difference in home healthcare nurses' job satisfaction. Home Healthcare Nurse 23 (12), 777-784.

Gurková E., Soósová S.M., Haroková S., Žiaková K., Šerfelová R. \& Zamboriová M. (2013) Job satisfaction and leaving intentions of Slovak and Czech nurses. International Nursing Review 60 (1), 112-121.

Hampton G.M. \& Peterson R.T. (2012) Job satisfaction of certified nurse midwives: an examination. Administrative Issues Journal 2, 112-126.

Hasselhorn H.M., Tackenberg P. \& Mueller B. (2003) Working Conditions and Intent to Leave the Profession among Nursing Staff in Europe. Working Life Research Report 7, National Institute for Working Life, Stockholm.

Hasselhorn H.M., Conway P.M., Widerszal-Bazyl M. et al. (2008) Contribution of job strain to nurses' consideration of leaving the profession - results from the longitudinal European Nurses' Early Exit Study. Scandinavian Journal of Work, Environment \& Health Suppl. 6, 75-82.

Hayes L.J., O’Brien-Pallas L., Duffield C. et al. (2012) Nurse turnover: a literature review - an update. International Journal of Nursing Studies 49 (7), 887-905.

Lazarus J., Rasch V. \& Liljestrand A. (2005) Midwifery at the crossroads in Estonia: attitudes of midwives and other key stakeholders. Acta Obstetricia et Gynecologica Scandinavica 84, 339-348.

Leung S.K., Spurgeon P.C. \& Cheung H.K. (2007) Job satisfaction and stress among ward-based and community-based psychiatric nurses. Hong Kong Journal of Psychiatry 17 (2), 45-54.

Li J. \& Lambert V.A. (2008) Job satisfaction among intensive care nurses from the People's Republic of China. International Nursing Review 55, 34-39.

Meeusen V., van Dam K., van Zundert A. \& Knape J. (2010) Job satisfaction amongst Dutch nurse anaesthetists: the influence of emotions on events. International Nursing Review 57, $85-91$.

Mueller C.W. \& McCloskey J.C. (1990) Nurses' job satisfaction: a proposed measure. Nursing Research 39, 113-117.

O'Keeffe A.P., Corry M. \& Moser D.K. (2013) Measuring job satisfaction of advanced nurse practitioners and advanced midwife practitioners in the Republic of Ireland: a survey. Journal of Nursing Management 2013 Jul 4. doi: 10.1111/ jonm.12096. [Epub ahead of print].

Oncel S., Ozer Z.C. \& Efe E. (2007) Work-related stress, burnout and job satisfaction in Turkish midwives. Social Behavior and Personality 35 (3), 317-328.

Prosen M. \& Piskar F. (2013) Job satisfaction of Slovenian hospital nursing workforce. Journal of Nursing Management 2013 Jul 22. doi: 10.1111/jonm.12121. [Epub ahead of print].

Ravari A.L.I., Bazargan M., Vanaki Z. \& Mirzaei T. (2012) Job satisfaction among Iranian hospital-based practicing nurses: examining the influence of self-expectation, social interaction and organisational situations. Journal of Nursing Management 20 (4), 522-533.

Rouleau D., Fournier P., Philibert A., Mbengue B. \& Dumont A. (2012) The effects of midwives' job satisfaction on burnout, intention to quit and turnover: a longitudinal study in Senegal. Human Resources for Health Available at: http:// link.springer.com/article/10.1186\%2F1478-4491-10-9\#page1, accessed 21 January 2014.

Shen J., Cox A. \& McBride A. (2004) Factors influencing turnover and retention of midwives and consultants: a literature review. Health Services Management Research 17 (4), 249262. 
Simon M., Müller B.H. \& Hasselhorn H.M. (2010) Leaving the organization or the profession - a multilevel analysis of nurses' intentions. Journal of Advanced Nursing 66 (3), 616-626.

Skinner V., Madison J. \& Humphries J.H. (2012) Job satisfaction of Australian nurses and midwives: a descriptive research study. Australian Journal of Advanced Nursing 29 (4), 19-27. Stordeur S., D'Hoore W., der van Heijden B., Dibisceglie M., Laine M. \& der van Schoot E. (2003) Leadership, job satisfaction and nurses' commitment. In Working Conditions and Intent to Leave the Profession among Nursing Staff in Europe (H.M. Hasselhorn, P. Tackenberg \& B. Mueller eds),
Working Life Research Report 7, pp. 28-45. National Institute for Working Life, Stockholm.

Takase M. (2010) A concept analysis of turnover intention: implications for nursing management. Collegian 17 (1), 3-12.

Wilkes R.C. \& Bartley S.J. (2007) A model for career planning in healthcare: investing in a career development program will retain workers for growth. Online Journal for Workforce Education and Development 2 (3), Available at: http://opensiuc.lib.siu.edu/cgi/viewcontent.cgi article $=1048 \&$ context $=0 j-$ wed, accessed 21 January 2014. 